\title{
Economic valuation of cultural heritage sites: A choice modeling approach
}

\author{
Andy S. Choi ${ }^{\mathrm{a}, *}$, Brent W. Ritchie ${ }^{\mathrm{b}}$, Franco Papandrea ${ }^{\mathrm{c}}$, Jeff Bennett ${ }^{\mathrm{a}}$ \\ ${ }^{a}$ Crawford School of Economics and Government, The Australian National University, ACT 0200, Australia \\ ${ }^{\mathrm{b}}$ School of Tourism, The University of Queensland, QLD 4072, Australia \\ ${ }^{\mathrm{c} C o m m u n i c a t i o n}$ and Media Policy Institute, Building 1, University of Canberra, ACT 2601, Australia
}

\section{A R T I C L E I N F O}

\section{Article history:}

Received 7 September 2007

Accepted 28 February 2009

\section{JEL classification:}

Q51

C51

Keywords:

Choice modeling

Cultural heritage site

Nonmarket valuation

Mixed logit

\begin{abstract}
A B S T R A C T
Despite growing attention by researchers and policy makers on the economic value of cultural heritage sites, debate surrounds the use of adequate methods. Although choice modeling techniques have been applied widely in the environmental economics field, their application in tourism and cultural economics has been much more limited. This paper contributes to the knowledge on the economic valuation of cultural heritage sites through a national choice modeling study of Old Parliament House, Australia. The study sought to value marginal changes in several attributes of this site and revealed that only some of them are valued positively: extending the period of temporary exhibitions, hosting various events, and having 'shop and café' and 'fine dining'. Advantages of using a mixed logit model are provided and managerial and policy implications are discussed.
\end{abstract}

(c) 2009 Elsevier Ltd. All rights reserved.

\section{Introduction}

Throughout the past two decades, the estimation of economic values of cultural goods and services has drawn the attention of economists (Kaminski, McLoughlin, \& Sodagar, 2007; Navrud \& Ready, 2002; Noonan, 2003; Venkatachalam, 2004). As Mazzanti (2002: p. 543) observed '[v]aluation is a central issue for cultural policy given cultural markets concerning heritage do not reflect the value users and society attach to the services provided by institutions.' Cultural goods and services contribute to social welfare and have public good characteristics that constitute legitimate arguments for the public provision of subsidies. However, questions remain regarding the level of the financial support that should be provided for cultural goods such as those supplied by public heritage institutions and cultural heritage sites.

Although there is a growing recognition of the broader economic value of cultural goods by academics, government policy makers and industry, no studies have been undertaken in Australia to estimate their economic value across the whole nation. In part this is due to difficulties in obtaining relevant market data and the

\footnotetext{
* Corresponding author. Permanent address: 291-18 Yeoungwoon-Dong, DongGu, Daejeon 300-120, South Korea. Tel.: +82 104772 9677; fax: +61 261258448. E-mail addresses: kecc21@hanmail.net (A.S. Choi), b.ritchie1@uq.edu.au (B.W. Ritchie), franco.papandrea@canberra.edu.au (F. Papandrea), jeff.bennett@ anu.edu.au (J. Bennett).
}

consequential need to use stated preference methodologies, such as the contingent valuation (CVM) and choice modeling (CM). The use of $\mathrm{CM}$ to estimate cultural values has so far been limited, though growing with CVM being dominant in the field (Kaminski et al., 2007; Noonan, 2003). Morey and Rossmann (1999) were the first to apply CM to cultural heritage with their research on air pollution policies. Other studies include Maddison and Foster (2003), Mazzanti (2003), Mazzanti (2002), Morey and Rossmann (2003), and Rolfe and Windle (2003).

The aim of this paper is to contribute knowledge on the economic valuation of cultural heritage sites. It reports results of a CM study to estimate the economic values of the diverse attributes of a cultural heritage site, Old Parliament House in Canberra, Australia. It applies the technique to both users and nonusers of the site making the scope of this paper unique.

Estimates of this kind are of value to both policy makers and managers of cultural institutions. To policy makers, the research provides a measure of the extent to which policies supporting cultural heritage sites are consistent with community expectations. To managers of cultural heritage sites, the research provides empirical guidance on the relative value that the wider community places on the services and facilities provided by the sites. As sites are actively reacting to community valuations of the benefits they offer to both visitors and nonvisitors, the research findings can help managers make more informed decisions on programs and activities that better reflect community expectations. 


\section{The economic valuation agenda}

Hansen, Trine, and Wanhill (1998) attribute a growing interest in cultural and heritage economics to two main factors. The first is the increasing interest in the interaction between expanded leisure time and increased demand from visitors to cultural and heritage attractions. The second reason relates to shifts in government policy towards market economics and curtailment of public spending. Cultural activities have public good attributes that contribute to society's well-being. Their characteristics often provide legitimate arguments for public provision of subsidies. However, questions remain over the level of support for public heritage sites and attractions, and decisions made by heritage managers need to consider the economic consequences of their actions, along with the educational, social and environmental impacts.

To date research on the value of cultural and heritage attractions has focused on the educational value of such attractions and heritage sites. A study by Garnett (2002) of over 180 publications on the impact of science centers and museums found that $87 \%$ concentrated on personal impacts, while only $9 \%$ examined the societal value, and $4 \%$ focused on the economic value of the institutions. This is due, in part, to cultural heritage sites having both market and nonmarket goods characteristics that are difficult to value. Valuation of nonmarket goods (such as heritage sites) has received considerable attention from environmental economics' practitioners, and there is a large amount of related literature (see Mitchell and Carson (1989) and Herath and Kennedy (2004) for a summary). However, few studies have been undertaken to place an economic value on cultural heritage sites despite the debate over their value to society and the growth of cultural economics as a field of research and scholarship.

The application of economic techniques and models to value heritage sites can add to the understanding of the broader economic value of these assets to society. It is of interest because there are increasing demands on cultural institutions and a move away from a focus on educational/personal values to considerations of their broader economic values. As the government at many levels often contributes substantial funds to these heritage sites (from taxation revenues) there is a need to place an economic or monetary value on these nonmarket goods to assess the efficiency of funding policies. This need for knowledge and the development of suitable techniques to measure economic value could assist the development of better-targeted policies and help secure more effective support for heritage sites.

Typically in valuation studies the interest is in estimating total economic value, which includes not only use values (for example, activities and services), but also intangible nonuse values (for example, educational, bequest, and altruistic values) not normally captured in private market transactions. Total economic value can be estimated using stated preference nonmarket valuation techniques (Bateman et al., 2002; Bennett \& Blamey, 2001a; Hensher, Rose, \& Greene, 2005; Noonan, 2003), such as CVM and CM, outlined in Fig. 1. Recourse to such methods is necessary because cultural goods have the characteristics of public goods (that is, nonmarketed goods). Revealed preference methods are applicable only when data on market transactions or activities are present, which include a component reflecting the value of a good or service such as the cost of travel incurred in visiting a site (travel cost method), the extra price you need to pay to enjoy the good (hedonic pricing), or the cost you pay to avoid an inconvenience or hazard (averting behavior or market prices).

However, when reliable market data are not available researchers may need to create a hypothetical market to elicit consumer preferences. For example, cultural institutions and

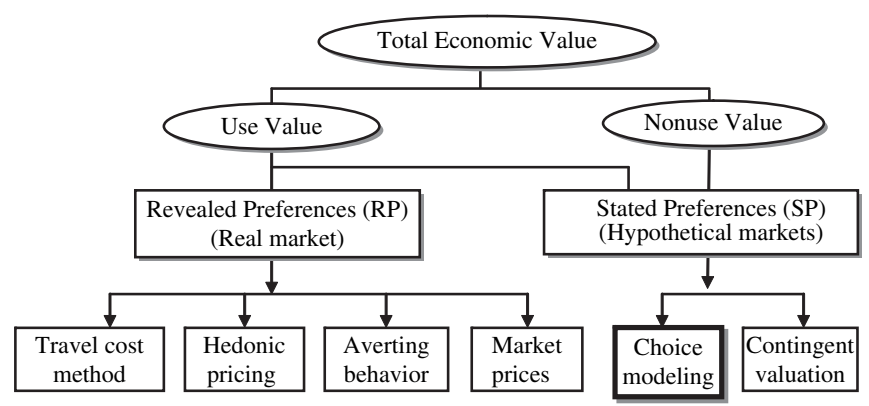

Fig. 1. Economic valuation techniques. Source: modified from Fig. 1.4 of Bateman et al. (2002: p. 30).

heritage sites often provide a variety of public contributions such as symbolic cultural items, historical value, social value, aesthetic value, spiritual value, educational value and shared experience (Hansen et al., 1998; Sable \& Kling, 2001; Throsby, 2001). These are public goods, and their economic values are not easily determined from transactions in actual markets.

In stated preference methods, respondents are asked to directly state how much they are willing to pay (or accept) for the given good (through CVM) or to choose the preferred option among a given set of choices (through CM).

Because of their capacity to capture both use and nonuse values stated preference techniques were used in this study. CVM as a nonmarket valuation technique has become popular and widely used over the past four decades (Noonan, 2003: p. 160; Venkatachalam, 2004: p. 90). In a CVM survey, respondents are asked to express their willingness to pay (WTP) for a good (or its change). There are several variations that are employed in CVM to elicit WTP information including, dichotomous choice (respondents are asked to say 'yes' or 'no' to a given proposition), 'payment cards' (respondents asked to choose from a list of prices the one that best reflects their WTP for the good), and 'auction bidding' (respondents asked to say 'yes' or 'no' to escalating or descending stated prices). The application of CVM to cultural goods is a relatively recent phenomenon with a limited range of examples available in the published literature (Navrud \& Ready, 2002: p. 257; Noonan, 2003: p. 161). Noonan (2003), in a bibliography of studies that have investigated cultural value through CVM, notes 35 studies since 1972 with the majority undertaken on specific cultural or historical sites.

Although CVM applications have not been without controversy, the reliability of the methodology when following a set of recommended good practices was endorsed by a 'blue-ribbon' panel of experts co-chaired by Nobel economics laureates Kenneth Arrow and Robert Solow (Arrow et al., 1993). In common with other stated preference techniques CVM estimates are prone to various types of bias (Bateman et al., 2002: pp. 296-342; Venkatachalam, 2004: pp. 90-117). They include an unreal/hypothetical scenario setting in which respondents may overstate or understate their true preferences (hypothetical or strategic bias); whether a resource or good is presented as a separate unit or as a part of aggregate goods (embedding or scope effect); how the information is given to respondents in surveys and whether alternative choices are provided (information or 'framing' effect); tendency to say 'yes' (yea-saying); whether respondents are asked to pay a high or low amount of payment (starting point bias); and influences from a payment method (payment vehicle bias).

At the same time, problems caused by poor designs and administrations for many cultural valuation studies are widely recognized. Common problems include poorly defined or implausible goods and a low response rate (Bennett \& Blamey, 2001b; 
Carson, Flores, Martin, \& Wright, 2001; Louviere, Hensher, \& Swait, 2000; Morrison, Bennett, \& Louviere, 1996; Noonan, 2003: p. 161; Tohmo, 2004: p. 230).

$\mathrm{CM}$ has emerged as an alternative method to the more widely used CVM (Bennett \& Blamey, 2001a). According to Kaminski et al. (2007) this method is the most recent innovation in valuation techniques yet few applications have been made to the valuation of heritage sites or their services. In their comprehensive review of the European literature, Kaminski et al. (2007) observed that from 17 nonmarket economic valuations in cultural sites in Europe 15 solely used CVM and only two used the CM approach. Those two applications improved the reliability of choice situations by involving a set of attributes in an experimental design. They reported museum-related use values, through either congestion costs at the British Museum (Maddison \& Foster, 2003) or marginal values of managerial options for the Galleria Borghese Museum in Italy (Mazzanti, 2003). Both of these studies focused on use values, and both had relatively low sample sizes (400 and 185 respectively).

\section{A choice modeling approach for valuing heritage sites}

\subsection{Choice modeling}

CM was designed to address the limitations of CVM and to improve the behavioral congruity of valuation models. It was pioneered by researchers including Louviere and Hensher (1982) and Louviere and Woodworth (1983). The technique is also known as choice experiments. It has been used in a wide range of areas including marketing and transportation, and applied to tourism (Correia, Santos, \& Barros, 2007; Lindberg, Dellaert, \& Romer Rassing, 1999; Morley, 1994), cultural resources (Mazzanti, 2002; Morey, Rossmann, Chestnut, \& Ragland, 1997), and environmental management (Adamowicz, Boxall, Williams, \& Louviere, 1998; Rolfe \& Bennett, 1996).

The CM technique is based on the 'characteristic theory of value' (Lancaster, 1966), in which a good is viewed as being a bundle of component attributes and their levels. For instance, an international rain forest conservation policy can be comprised of location (country), area (size), rarity, potential to visit, effect on local populations, special features of the area, and cost of the proposal (Rolfe \& Bennett, 2001). Remnant vegetation can be described in terms of rarity of species, ease of visit, area (size), and household cost (Morrison et al., 1996). Similarly, a museum can be described by information on conservation level/activity, access policy (visit hours), additional services, and entry fee (Mazzanti, 2003).

In order to measure nonmarket values in CM studies, series of questions called 'choice sets' are presented to survey respondents. For each question, respondents are asked to choose one preferred option from several alternatives. One of the choice options is usually given as a 'status quo' or 'no action' policy, whilst other 'change' options are designed using variations in the levels taken by constituent 'characteristics' or 'attributes'. One attribute typically represents a monetary variable (known as 'payment vehicle'), which enables the derivation of implicit prices.

Alternative choice options in a CM application can be presented to respondents in two formats: labeled (or alternative specific) or unlabelled (or generic) (Bennett \& Adamowicz, 2001: p. 54). The labeled format involves individual alternatives being labeled with specific names (for example, proposed policies, site names, and locations) so that respondents are able to express their average unobserved utilities for each alternative. The labels work as attributes that are constants for their alternatives, providing additional information, and making respondents' choices more realistic because of their influences on consumers' decisions (Hensher et al., 2005: p. 113). Moreover, this format accommodates expectations and experiences of respondents, as economic theory recommends (Blamey, Louviere, \& Bennett, 2001: p. 138). The second format provides generic titles such as 'Options A and B', or 'Alternatives A and B'. It can provide respondents with the opportunity to develop 'more informed and deliberated preferences' (Blamey et al., 2001: p. 138).

Using choice models, utilities of the given alternatives are derived from the options (choices) selected by the respondents. Respondents make 'trade-offs' according to the relative values of the given options and marginal utilities are estimated for the changes in individual attributes. The underlying theory explaining the observed choices is the random utility model (Louviere, 2001: pp. 14-15).

The main feature of the random utility model is that the utility of individuals cannot be directly observed by researchers. Although a portion of choice behavior (results from the choice process) can be explained, some fraction always remains unexplained (Louviere, 2001: p. 15; Morrison et al., 1996: p. 3; Rolfe, 1998: p. 33). Hence, the utility of the $i$ th alternative for individual $q\left(U_{i q}\right)$ can be described with two components:

$U_{i q}+V_{i q}=\varepsilon_{i q}$

$V_{i q}$ is the observable systematic (explainable) component, often called the observed, 'representative utility' or 'deterministic utility' (Louviere et al., 2000: p. 38; Morrison et al., 1996: p. 3; K. E. Train, 2003: p. 19). $\varepsilon_{i q}$ is the unobservable random (unexplainable) component and reflects 'unobserved individual idiosyncrasies of tastes' (Louviere et al., 2000: p. 38). The random component $\left(\varepsilon_{i q}\right)$ hinders our effort to 'understand perfectly and predict preferences; hence, the problem is inherently stochastic from the researcher's view, which naturally leads to formulating expressions for the probability of choice' (Louviere, 2001: p. 15).

In general, $V_{i q}$ is assumed to be a 'linear and additive form' of observed attributes $\left(X_{i q}\right)$ of alternatives, which 'maps the multidimensional attribute vector into a unidimensional overall utility' (Louviere et al., 2000: p. 42). For individual $q$ to choose the $i$ th alternative comprised of $k$ attributes $\left(X_{i q}\right), V_{i q}$ can be written as:

$V_{i q}=\sum_{k=1}^{K} \beta_{i k} X_{i k q}$

Once a random utility model is estimated, welfare estimates of alternatives, projects, or policies of concern can be calculated relative to the status quo. In many choice models, researchers are interested in the value of a marginal change in a single attribute. The WTP for the marginal change in the $k$ th attribute $\left(\beta_{k}\right)$ (also known as a 'part-worth' or 'implicit price') can be described as Equation (3):

$\mathrm{WTP}=-\frac{\beta_{k}}{\beta_{\mu}}$

\subsection{The study site}

Old Parliament House (OPH) was the first purposely-built home of the national parliament of Australia and was in use from 1927 to 1988, when the parliament was moved to its new home. It is located in the national capital city of Australia, Canberra. OPH is currently operating as a museum of social and political history, located in a nationally listed heritage building, and is described in its promotional literature as follows:

The significance of Old Parliament House today lies in its historical and social value to the Australian people. The House is 
a nationally significant 'museum of itself and of Australia's political heritage-so, as well as being a popular tourist destination, it is also a precious place which needs conservation (OPH, 2007).

In addition to being a museum of political history, OPH also provides a range of permanent and temporary exhibition services, traveling exhibitions, as well as organizing a range of related events such as lectures and seminars for the general public. Auxiliary facilities available on the site for public use include, a café, restaurant, shop and conference rooms.

\subsection{Questionnaire design and administration}

To implement a nationwide survey, questionnaires were prepared and improved through close consultation with OPH officials and focus groups. Five attributes were distinguished at the beginning of the study. They were 'Landmark building and collections', 'Exhibitions', 'Programs', 'Facilities', and 'Entry fees'.

Through the consultation process with the managers of $\mathrm{OPH}$, landmark building and collections were replaced by access policy (replications of original items). Landmark building was excluded from the list of attributes because it was not subject to any meaningful change and thus could not be included in the choice modeling research. Other attributes remained the same, but were more clearly articulated. In particular, entry fees were replaced by annual tax, because tax can minimize the strategic bias inherent in this type of study. After three focus group studies in March 2006, the final sets of attributes and their levels were prepared.

The attributes and their level changes (from their current to alternative levels) are shown in Table 1. Most of the level changes were practically determined by managerial considerations. For example, in order to reduce damage to its building and fabric (furniture, carpets, curtains, and décor), OPH considered increasing the amount of replicated items displayed by up to $50 \%$. Furthermore, $\mathrm{OPH}$ has considered implementing interactive (audiovisual) displays. In the case of 'Funding', however, an AU\$2.00 (AU $\$ 1.00=\mathrm{US} \$ 0.75)$ tax payment per household was calculated by dividing the reported annual revenue from the government-AU\$15.6 million-by the number of households in Australia-7,850,576.5 (Australian Bureau of Statistics, 2006). In addition, as OPH currently charges an AU $\$ 2.00$ entry fee for adults, the summary table of the questionnaires provided this information as a part of the 'Funding' information.

Based on the attributes and their level changes, an experimental design was constructed. A D-efficient design was used to maximize the efficiency of parameter estimates by providing minimum values of all the elements in the variance-covariance matrix (Bliemer \& Rose, 2005; Ferrini \& Scarpa, 2007; Kuhfeld, Tobias, \& Garratt, 1994;
Rose \& Bliemer, 2005: p. 1). The design that provides the best precision in parameter estimations is a ' $D$-optimal' design.

The $D$-optimal design for this research was prepared with 20 choice sets, and these were divided into four versions. Therefore, each questionnaire included one of the four versions with five different choice sets. Furthermore, each choice set had four choice options: Option A (the 'status quo' option), Options B and C (alternative options), and Option D ('Not Sure' option). The 'Not Sure' (no choice) option was included as part of the choice sets to avoid forcing choices on respondents (Blamey et al., 2001).

In the questionnaires overall questions were grouped into three major sequential sections: introductory, valuation and final. The introductory section provided respondents with basic information, including the aim of the survey and what was expected of respondents, and posed questions to elicit information on the respondent's experience and attitudinal disposition. In the second section (the valuation section), respondents were asked to make a set of choices in response to several options constructed according to the a priori experimental design described above. The final section elicited responses to a set of sociodemographic questions.

The questionnaires were developed through focus groups and pilot studies on the campus of the Australian National University, and sent to 4000 randomly selected people (nationwide) between March and May 2006. There were 785 useful responses collected. Considering that people with a high level of interest or involvement in culture are more likely to be interested in reading the questionnaires (self-selection), the low response rate of the study (about $20 \%$ ) may cause higher implicit price estimates. While the questionnaires were carefully designed and tested by focus groups and a pretest, two contacts were implemented, due to the budget limitation, instead of the five standard contacts (Dillman, 2000). The first questionnaire booklets were mailed out with a separate cover letter, followed by reminder (and 'thank you') postcards one week later. Furthermore, a chance to win an AU\$500 (US\$375) lottery prize was offered as an incentive.

\section{Results}

Sample characteristics in socio-demographics are shown in Table 2. Compared with census data from the Australian Bureau of Statistics (2006), the sample over represents females by $10 \%$, the old (aged more than 55) by $18 \%$, and people with a university/ college degree by $3 \%$, and under represents households with incomes of more than $\$ 46,020$ by $5 \%$.

Most level changes of the eight attributes for OPH (listed in Table 1) were coded as linear variables. REP, TEM, TAX were treated as interval variables, while NPG, INT, EXH, EVE were coded as dummy

Table 1

Attributes and their levels for OPH.

\begin{tabular}{|c|c|c|c|}
\hline Attribute & Current situation & Levels & Variable name \\
\hline Access policy & 0\% replica (100\% original) & 0\%, 10\%, 30\%, 50\% replica & REP \\
\hline Exhibitions & $\begin{array}{l}\text { National Portrait Gallery } \\
\text { Temporary exhibitions (every } 8 \text { months) }\end{array}$ & $\begin{array}{l}\text { Dummy ( } 0 \text { without, } 1 \text { with) } \\
\text { Every } 2,4,6 \text { months }\end{array}$ & $\begin{array}{l}\text { NPG } \\
\text { TEM }\end{array}$ \\
\hline Programs & $\begin{array}{l}\text { Interactive display } \\
\text { Traveling exhibitions } \\
\text { Events }\end{array}$ & $\begin{array}{l}\text { Dummy ( } 0 \text { without, } 1 \text { with) } \\
\text { Dummy (one traveling, all traveling) } \\
\text { Dummy ( } 0 \text { without, } 1 \text { with) }\end{array}$ & $\begin{array}{l}\text { INT } \\
\text { EXH } \\
\text { EVE }\end{array}$ \\
\hline Facilities & Shop, café, fine dining restaurant, and conference rooms & $\begin{array}{l}\text { None } \\
\text { Shop and café } \\
\text { Shop and café, fine dining } \\
\text { Shop and café, fine dining, conference rooms }\end{array}$ & FAC \\
\hline Funding (AU\$) & $\$ 2$ annual tax & $1 \$, \$ 4, \$ 6, \$ 8, \$ 10$ & TAX \\
\hline
\end{tabular}


Table 2

Sociodemographic and economic characteristics of the sample, $\mathrm{OPH}$.

\begin{tabular}{|c|c|c|c|c|c|c|c|c|c|}
\hline Variable & & Count & $\%$ & ABS & Variable & & Count & $\%$ & ABS \\
\hline \multirow[t]{2}{*}{ Gender } & Male & 310 & 39.7 & 49.5 & Education & No schooling & 1 & 0.1 & \\
\hline & Female & 471 & 60.3 & 50.5 & & Primary only & 35 & 4.5 & \\
\hline \multirow[t]{7}{*}{ Age } & $17-24$ & 18 & 2.3 & 9.8 & & Junior/year 10 & 138 & 17.7 & \\
\hline & $25-34$ & 89 & 11.4 & 19.6 & & Senior/year 12 & 177 & 22.7 & \\
\hline & $35-44$ & 141 & 18.0 & 20.5 & & Diploma/certificate & 185 & 23.7 & $51.5^{\mathrm{a}}$ \\
\hline & $45-54$ & 148 & 18.9 & 19.1 & & University/tertiary & 214 & 27.4 & \\
\hline & $55-64$ & 166 & 21.2 & 15.0 & & Other & 32 & 4.1 & \\
\hline & $65-74$ & 144 & 18.4 & 9.6 & Marriage & Single (never married) & 107 & 13.7 & 31.8 \\
\hline & $75+$ & 76 & 9.7 & 6.5 & & Married/living together & 501 & 64.2 & 54.6 \\
\hline \multirow[t]{7}{*}{ Income (AU\$) } & Under $\$ 9203$ & 35.0 & 5.0 & 2.7 & & Divorced/separated & 101 & 12.9 & 7.4 \\
\hline & $\$ 9204-18,230$ & 115.0 & 16.3 & 16.8 & & Widowed & 68 & 8.7 & 6.1 \\
\hline & $\$ 18,231-28,319$ & 102.0 & 14.4 & 13.8 & Household size & 1 & 226 & 29.5 & \\
\hline & $\$ 28,320-36,815$ & 92.0 & 13.0 & 10.4 & & 2 & 289 & 37.7 & \\
\hline & $\$ 36,816-46,019$ & 75.0 & 10.6 & 10.3 & & 3 & 100 & 13.0 & \\
\hline & $\$ 46,020-92,039$ & 211.0 & 29.9 & 33.0 & & 4 & 87 & 11.3 & \\
\hline & Over $\$ 92,040$ & 76.0 & 10.8 & 13.0 & & $>5$ & 65 & 8.5 & \\
\hline
\end{tabular}

a This is the percentage of people with nonschool educational qualifications of all persons aged 15-64 years in 2005. The sample has 51.0\%.

variables. However, as FAC is qualitative (ordinal) variable with four levels, its levels were coded using effect codes with three variables (Hensher et al., 2005: p. 120). The current level with full facilities ('shop and café, fine dining, and conference rooms') was taken as the base level against which other levels with fewer facilities were coded - with no facility (FACO), with 'shop and café' (FAC1), and with 'shop and café, and fine dining' (FAC2).

There were 3925 choices-785 respondents answered five choice sets each. When the frequencies of the four choice options are compared, their shares are 45.1, 27.2, 20.8, and 6.9\%, respectively. Three alternative specific constants (ASCs) were used to differentiate among the four options. As a result, utility functions were formulated as follows:

$$
\begin{aligned}
& \mathrm{U}(\mathrm{A})=\sum \beta_{k} X_{k} \\
& \mathrm{U}(\mathrm{B})=\mathrm{ASC}_{\mathrm{B}}+\sum \beta_{k} X_{k} \\
& \mathrm{U}(\mathrm{C})=\mathrm{ASC}_{\mathrm{C}}+\sum \beta_{k} X_{k} \\
& \mathrm{U}(\mathrm{D})=\mathrm{ASC}_{\mathrm{D}}
\end{aligned}
$$

In order to estimate a mixed logit model, ten variables (for the eight attributes) plus the three ASCs were checked to determine whether their parameters are fixed or random. A random parameter indicates that the sample has a distribution of preferences for the attribute, which cannot be fully represented by a single mean parameter. That is, the parameter weight for the attribute varies across its respondents according to unknown and unobserved sources of heterogeneity (Hensher et al., 2005: p. 633). One hundred Halton draws (K. Train, 1999) were applied to simulate distributions that were assumed to be normal, and panel formulation was used to distinguish answers from the same respondents.

The estimation results of the model are shown in Table 3. Nine parameters-for $A_{S C}, A_{B} C_{D}$, NPG, TEM, INT, EXH, EVE, FACO, and FAC1 - were found to be random, whose derived standard deviations are significantly different from zero. This means that the estimated parameters are dispersed around their means thus demonstrating the presence of heterogeneity in the estimates (Hensher et al., 2005: p. 633). The INT parameter was significant when fixed and became insignificant when treated as random. Also, the REP parameter was insignificant and its exclusion improved the model fit. Furthermore, statistical distributions of some parameter estimates cover both negative and positive space. For instance, the parameter estimates of TEM and EVE spread over ranges, respectively (the $95 \%$ confidence interval) from -0.7737 to 1.3494 , and from -0.8901 to 1.6278 . The distributions symbolize the presence of different sensitivities or heterogeneous preferences that might be held by the respondents. Preference heterogeneity might be caused by different characteristics of respondents, either sociodemographic or/and attitudinal (Choi, Papandrea, \& Bennett, 2007; Johansson, Heldta, \& Johansson, 2006). However, further implications of these distributions are beyond the scope of this paper.

According to the results, increasing tax payment for OPH (TAX)

\begin{tabular}{|c|c|c|c|c|}
\hline Attribute & Coeff. & Std. err. & $t$-Ratio & $p$-Value \\
\hline$\overline{\mathrm{ASC}_{\mathrm{B}}{ }^{\mathrm{a}}}$ & 0.3969 & 0.2543 & 1.5604 & 0.1187 \\
\hline $\operatorname{ASC}_{C}{ }^{a}$ & $0.5855^{* *}$ & 0.2630 & 2.2265 & 0.0260 \\
\hline $\mathrm{ASC}_{\mathrm{D}}{ }^{\mathrm{a}}$ & $-3.7563^{* * *}$ & 0.5578 & -6.7342 & 0.0000 \\
\hline NPG & 0.0653 & 0.1100 & 0.5935 & 0.5528 \\
\hline TEM & $0.2878^{* * *}$ & 0.0504 & 5.7077 & 0.0000 \\
\hline INT & 0.2005 & 0.1377 & 1.4560 & 0.1454 \\
\hline EXH & 0.0365 & 0.1248 & 0.2923 & 0.7701 \\
\hline EVE & $0.3688^{* * *}$ & 0.1155 & 3.1922 & 0.0014 \\
\hline $\mathrm{FACO}^{\mathrm{b}}$ & $-0.6617^{* * *}$ & 0.1038 & -6.3761 & 0.0000 \\
\hline $\mathrm{FAC}^{\mathrm{b}}$ & $-0.2271^{* *}$ & 0.1134 & -2.0018 & 0.0453 \\
\hline $\mathrm{FAC}^{\mathrm{b}}$ & $0.4396^{* * *}$ & 0.1285 & 3.4201 & 0.0006 \\
\hline TAX & $-0.0795^{* * *}$ & 0.0211 & -3.7692 & 0.0002 \\
\hline \multicolumn{5}{|c|}{ Standard deviation parameters } \\
\hline $\mathrm{NsASC}_{B}{ }^{\mathrm{C}}$ & $1.9379 * * *$ & 0.1559 & 12.4291 & 0.0000 \\
\hline $\operatorname{NsASC}_{C}{ }^{\mathrm{c}}$ & $0.2641^{*}$ & 0.1515 & 1.7430 & 0.0813 \\
\hline NsASC $_{D}{ }^{c}$ & $5.1388^{* * *}$ & 0.4624 & 11.1123 & 0.0000 \\
\hline $\mathrm{NsNPG}^{\mathrm{c}}$ & $1.3063^{* * *}$ & 0.1470 & 8.8863 & 0.0000 \\
\hline NSTEM $^{\mathrm{c}}$ & $0.5416^{* * *}$ & 0.0353 & 15.3582 & 0.0000 \\
\hline NsINT $^{c}$ & $1.9569^{* * *}$ & 0.1980 & 9.8853 & 0.0000 \\
\hline $\mathrm{NsEXH}{ }^{\mathrm{c}}$ & $0.5180^{* *}$ & 0.2055 & 2.5209 & 0.0117 \\
\hline $\mathrm{NsEVE}^{\mathrm{c}}$ & $0.6423^{* * *}$ & 0.1704 & 3.7687 & 0.0002 \\
\hline $\mathrm{NsFACO}^{\mathrm{C}}$ & $0.5074^{* * *}$ & 0.1403 & 3.6164 & 0.0003 \\
\hline $\mathrm{NsFAC}^{\mathrm{c}}{ }^{\mathrm{c}}$ & $1.1247^{* * *}$ & 0.1041 & 10.7998 & 0.0000 \\
\hline \multicolumn{5}{|l|}{ Model fit } \\
\hline$\overline{\mathrm{LL}}$ & -3474.81 & & & \\
\hline Pseudo $R^{2}$ & 0.35 & & & \\
\hline $\mathrm{LR}^{\mathrm{d}}$ & $3752.56^{* * *}$ & & & \\
\hline
\end{tabular}
and reducing facilities (FAC) have negative utilities, in general,

Table 3

Estimation results from a mixed logit model for $\mathrm{OPH}$.

*Significant at the 0.10 level, ${ }^{* *}$ significant at the 0.05 level, ${ }^{* * *}$ significant at the 0.01 level.

a ASCs are the alternative specific constants that differentiate between the current status (Option $A$ ) and other alternative options-Option $B\left(A_{S C}\right)$, Option $C$ $\left(\mathrm{ASC}_{\mathrm{C}}\right)$, and Option D $\left(\mathrm{ASC}_{\mathrm{D}}\right)$.

b FACO, FAC1, and FAC2 are level changes, effect coded, reducing 'shop and cafe, fine dining, conference rooms' (full facilities), 'fine dining and conference rooms', and 'conference rooms', respectively from the full facilities.

c These are derived standard deviations of parameter distributions, assumed to be normally distributed.

${ }^{d}$ LR is the result of a nested log-likelihood ratio test between this model and a multinomial logit model that has the same variables without random parameters. 
Table 4

Marginal and aggregate WTP estimates, OPH.

\begin{tabular}{|c|c|c|c|}
\hline Attribute & Marginal WTP (AU\$) ${ }^{a}$ & Aggregate WTP $(A U \$)^{b}$ & Change \\
\hline$\overline{\text { TEM }}$ & $\$ 3.62(2.11,7.66)$ & $\$ 17,048,721.56$ & Longer temporary exhibitions by one month \\
\hline EVE & $\$ 4.64(1.40,11.25)$ & $\$ 21,846,484.20$ & Hosting various events \\
\hline $\mathrm{FAC}(1)$ & $\$ 5.46(1.08,14.30)$ & $\$ 25,738,273.26$ & Having 'shop and café' \\
\hline $\mathrm{FAC}(2)$ & $\$ 13.85(6.89,32.21)$ & $\$ 65,229,031.08$ & Having 'shop and café' and 'fine dining' \\
\hline $\mathrm{FAC}(3)$ & $\$ 13.97(7.49,31.64)$ & $\$ 65,790,289.29$ & Keeping all the facilities from out of service \\
\hline $\mathrm{FAC}(4)$ & $\$ 8.38(2.81,21.62)$ & $\$ 39,490,757.82$ & Having 'fine dining' \\
\hline $\mathrm{FAC}(5)$ & $\$ 0.12(-6.19,6.18)$ & $\$ 561,258.21$ & Having 'conference rooms' \\
\hline
\end{tabular}

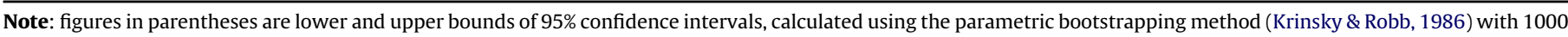
simulated estimates.

a WTP is expressed as an annual household payment on average in AU\$ (AU $\$ 1.00=$ US $\$ 0.75$ ).

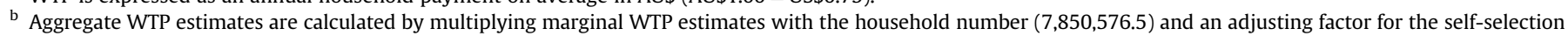
bias (0.6).

while having extended temporary exhibitions (TEM) and various events (EVE) have positive utilities. Three parameters were effect coded for FAC (FACO, FAC1, and FAC2 in Table 3). Hence, the parameter estimate of the base level (full facilities) could be derived using the results, to be 0.4491 . As effect-coded estimates represent relative utilities, negative signs for facility reductions can be interpreted as positive utilities from the facilities available in the current situation. Respondents are thus more sensitive to the reductions of 'shop and café' and 'fine dining', than that of 'conference rooms'. Furthermore, the positive parameter estimate for the frequency in the temporary exhibitions (TEM) suggests support for less frequent (or longer) temporary exhibitions. Respondents were not sensitive to changes in the other attributes at the 0.05 level of significance.

WTP estimates for the attributes for OPH were calculated using Equation (3). WTP estimates for significant attributes are reported in Table 4. Particularly, facility-specific WTP estimates were further extrapolated from the results for each level change of FAC and are included in the table. Hosting 'shop and café' and 'fine dining' are valued at respectively AU\$5.46 and AU\$8.38 annually per household. The contribution from having 'conference rooms' is AU\$0.12 but this is not significantly different from zero, considering its confidence interval.

Nationwide welfare benefits (aggregate WTP estimates) were calculated by multiplying each marginal WTP estimate with the number of Australian households (7,850,576.5) in 2005 (Australian Bureau of Statistics, 2006) and an adjusting factor of 0.6-taking only $60 \%$ of the original estimate-in order to infer a conservative figure that addresses the self-selection bias, as suggested by Morrison (2000) and Morrison and MacDonald (2006). The aggregate WTP estimates for the specified changes in TEM and EVE are respectively AU $\$ 17.0$ million and AU $\$ 21.8$ million annually. Those for 'shop and café', 'fine dining' and 'conference rooms' are respectively AU\$25.7 million, AU\$39.5 million, and AU\$0.6 million annually.

Although the marginal and aggregate estimates seem to be 'usevalues' oriented, they are also expected to include aspects of 'nonuse-values' such as pride, identity, or iconic values. However, the latter were not expressed separately in the estimates due to measuring difficulties, as they are usually intangible.

These results provide several policy and managerial implications. Firstly, aggregate welfare benefits of the various changes can be compared with their implementation costs. When the benefits are larger than the costs, the changes could be justified. Secondly, the estimated total economic value of the status quo equals AU $\$ 224.0$ million (US\$168.0 million). Considered in the light of its annual governmental support of AU\$13.8 million, the main source of revenue, the public benefit contributed by OPH far outweighs (16 times larger) its governmental subsidy. These figures can be also compared with other revenue sources, including entry fees, which is about $10 \%$ of the governmental support. It can be inferred that the overall public contributions from the cultural heritage site (both tangible and intangible) are considerably larger than the provision cost. The third implication is that the estimated aggregate welfare benefit from all facilities currently available is AU\$65.8 million annually. The use of conference rooms brings a minimal contribution. Finally, respondents are generally not sensitive (at the 0.05 level) to some proposed changes, such as increasing replicated items (REP), hosting a gallery within the site (NPG), providing interactive displays (INT), and having all exhibitions traveling (EXH).

\section{Conclusion}

Although the economic valuation of cultural goods and services has gained increasing interest from policy makers and cultural economists, few studies have been undertaken to place an economic value on cultural heritage sites, despite the debate over their value to society and their level of government funding and support. Although previous research has been conducted on the economic valuation of cultural heritage sites, few studies have examined both use and nonuse values through the application of choice modeling techniques, despite increased use of choice modeling in environmental economics and tourism more generally.

This paper examined the economic values of changing various services provided by a cultural heritage site in Australia to address this deficiency. A choice modeling study was implemented and the collected data were analyzed using a mixed logit model. A conservative approach was undertaken measuring attributes that could be changed by managers as well as using an adjusting factor of $0.6-60 \%$ of the original estimate - to minimize self-selection bias.

Several recommendations inferred from the study results can be summarized as follows. First, respondents prefer to have longerlasting (less frequent) temporary exhibitions, various events, and the facilities currently available. Managers may consider extending the period of temporary exhibitions and raise publicity of various events they currently have. The second point relates to the neutrality of changes in some attributes. The overall preferences of respondents are not significantly influenced by the amount of replicated items (for visitors' touching), the presence/absence of the gallery, the provision of audiovisual effects for more effective displays, and making all exhibitions traveling across the country. Although any generalization requires further studies on heterogeneity issues, decision makers may consider their closure or provide them in a limited fashion. The third recommendation comes from the comparison between the two previous implications. People are only sensitive to major changes such as in-house exhibitions, events, and facilities, while not much so to other quality changes such as replicated items, a high level of interpretation, and out-of-house 
exhibitions. The above point might be applicable to other similar heritage sites such as exhibition halls and museums. The final recommendation is about facilities. As a heritage-listed building, $\mathrm{OPH}$ may consider the optimal level of facilities available to the visitors. Given the minimal sensitivity people hold on 'conference rooms', OPH may consider alternative programs substituting conferences, while enhancing the other facilities.

Above all, when their aggregate values nationwide (welfare effects) are considered, the currently available services and facilities generate a total economic value of AU $\$ 224.0$ million annually. This aggregate value consists of AU\$136.4 million from temporary exhibitions that are organized every eight months; AU\$21.8 million from various weekly events such as special tours, lunch talks with special guests, kids' activities, and concerts; and AU\$65.8 million from facilities such as shop and café, fine dining, and conference rooms.

This type of information can be valuable to managers of heritage sites. For example, it can assist managers to optimize their budget allocations and to guide efforts to achieve proper balance between use value derived by visitors and overall welfare accruing to the larger community including nonvisitors. As most cultural heritage sites provide both use and nonuse values, however, practical decisions may depend on institutional rationales that each site bears. Some sites may focus on the maximum impact on the use values visitors enjoy, while others may give greater considerations to benefits accruing to the wider community. Hence, it can be argued that valuation studies provide management with additional information about the likely outcomes of potential changes. This is only one of several inputs to the decision making process that is concerned not only with economic valuations, but also with the impact that heritage sites are likely to have on education and society more broadly.

Furthermore, choice modeling as a valuation method, although subject to some of the limitations of CVM, is likely to be less prone to other potential weaknesses. For instance, choosing a preferred option from among several is likely to be less vulnerable to hypothetical bias because such a choice process has a greater semblance to real market actions, where consumer preferences are normally expressed as choices rather than direct payment arguments. Another important feature of choice modeling is its ability to examine impacts from various changes across several attributes in a single study, whose level changes are designed a priori through experimental designs. This study estimated expected values of some managerial options that are only possible through choice modeling. Other vulnerabilities such as scope effects, framing effects, and payment vehicle bias, however, might continue to be encountered.

It should be noted that the questionnaire administration method adopted in this study and the resulting low response rate are likely to have had some influence on the overall results. The adoption of two out of the five standard contacts suggested by Dillman (2000: p. 151) is likely to have contributed to the low response rate (about 20\%). As a result, the stated preferences might have been shifted upward due to the selection bias. Further research, especially at a national level, should consider ways to deal with nonresponse bias.

It is recommended that further research be undertaken to develop indicators on the economic value of different heritage sites in Australia and overseas and thus enhance the potential application of benefit transfer from individual studies to policy. The authors recommend a choice modeling approach to economic valuation to include both users and nonusers of heritage sites. However, further research could be undertaken on users or specific visitor segments at cultural heritage sites to provide a better understanding of the value of specific site programs and facilities for different target groups. For instance, research with school teachers who organize school excursions to cultural heritage sites, and parents who often contribute funding for such trips, could be undertaken to gain a better understanding of the educational value of sites and potential changes to heritage sites through educational resources and programs for this particular market. Not only would this assist managerial decision making by indicating what programs are valued, but also what changes might lead to increased visitation to such sites.

\section{Acknowledgement}

The authors are grateful to the thoughtful comments from two anonymous reviewers. The data used in this paper are from research funded by the Sustainable Tourism Cooperative Research Centre (CRC), established by the Australian Commonwealth Government, and by the National Capital Attractions Association. Valuable assistance in experimental design and modeling from Dr. John Rose, Institute of Transport and Logistics Studies, University of Sydney, is gratefully acknowledged.

\section{Appendix A. Supplemental material}

Supplementary information for this manuscript can be downloaded at doi: 10.1016/j.tourman.2009.02.014.

\section{References}

Adamowicz, W., Boxall, P., Williams, M., \& Louviere, J. (1998). Stated preference approaches for measuring passive use values: choice experiments and contingent valuation. American Journal of Agricultural Economics, 80(1), 64-75.

Arrow, K., Solow, R., Portney, P. R., Leamer, E. E., Radner, R., \& Schuman, H. (1993). Report of the NOAA Panel on contingent valuation. Federal Register, 58(10), 4601-4614

Australian Bureau of Statistics. (2006). Themes. http://www.abs.gov.au/websitedbs/ D3310114.nsf/home/themes?opendocument Retrieved 19.08.06.

Bateman, I. J., Carson, R. T., Day, B., Hanemann, M., Hanley, N., Hett, T., et al. (2002). Economic valuation with stated preference techniques: A manual. Northampton, MA: Edward Elgar.

Bennett, J., \& Adamowicz, V. (2001). Some fundamentals of environmental choice modelling. In J. Bennett, \& R. Blamey (Eds.), The choice modelling approach to environmental valuation (pp. 37-69). Northampton, MA, USA: E. Elgar.

Bennett, J., \& Blamey, R. (2001a). Introduction. In J. Bennett, \& R. Blamey (Eds.), The choice modelling approach to environmental valuation (pp. 1-12). Northampton, MA, USA: E. Elgar.

Bennett, J., \& Blamey, R. (Eds.). (2001b). The choice modelling approach to environmental valuation. Northampton, MA, USA: E. Elgar.

Blamey, R., Louviere, J. J., \& Bennett, J. (2001). Choice set design. In J. Bennett, \& $\mathrm{R}$. Blamey (Eds.), The choice modelling approach to environmental valuation (pp. 133-156). Northampton, MA, USA: E. Elgar.

Bliemer, M. C. J., \& Rose, J. M. (2005). Efficient designs for alternative specific choice experiments. (No. ITLS working paper ITLS-WP-05-04). Sydney: University of Sydney.

Carson, R. T., Flores, N. E., Martin, K. M., \& Wright, J. L. (2001). Contingent valuation: controversies and evidence. Environmental and Resource Economics, 19(2), 173-210.

Choi, A. S., Papandrea, F., \& Bennett, J. (2007). Assessing cultural values: developing an attitudinal scale. Journal of Cultural Economics, 31, 311-335.

Correia, A., Santos, C. M., \& Barros, C. P. (2007). Tourism in Latin America: a choice analysis. Annals of Tourism Research, 34(3), 610-629.

Dillman, D. A. (2000). Mail and internet surveys. New York: John Wiley \& Sons.

Ferrini, S., \& Scarpa, R. (2007). Designs with a priori information for nonmarket valuation with choice experiments: a Monte Carlo study. Journal of Environmental Economics and Management, 53(3), 342-363.

Garnett, R. (2002). The impact of science centers/museums on their surrounding communities. Canberra: Questacon.

Hansen, B., Trine, H. C., \& Wanhill, S. (1998). The economic evaluation of cultural and heritage projects: conflicting methodologies. Tourism, Culture and Communication, 1(1), 27-48.

Hensher, D. A., Rose, J. M., \& Greene, W. H. (2005). Applied choice analysis: A primer. Cambridge: Cambridge University Press.

Herath, G., \& Kennedy, J. (2004). Estimating the economic value of Mount Buffalo National Park with the travel cost and contingent valuation methods. Tourism Economics, 10(1), 63-78.

Johansson, M. V., Heldta, T., \& Johansson, P. (2006). The effects of attitudes and personality traits on mode choice. Transportation Research Part A: Policy and Practice, 40(6), 507-525. 
Kaminski, J., McLoughlin, J., \& Sodagar, B. (2007). Economic methods for valuing European cultural heritage sites (1994-2006). In J. McLoughlin, J. Kaminski, \& B. Sodagar (Eds.), Perspectives on impact, technology and strategic management, Vol. 1 (pp. 98-121). Budapest: EPOCH.

Krinsky, I., \& Robb, A. L. (1986). On approximating the statistical properties of elasticities. Review of Economics and Statistics, 68, 715-719.

Kuhfeld, W. F., Tobias, R. R., \& Garratt, M. (1994). Efficient experimental design with marketing research applications. Journal of Marketing Research, 31, 545-557.

Lancaster, K. J. (1966). A new approach to consumer theory. Journal of Political Economy, 74, 132-157.

Lindberg, K., Dellaert, B. G. C., \& Romer Rassing, C. (1999). Resident tradeoffs: a choice modeling approach. Annals of Tourism Research, 26(3), 554-569.

Louviere, J. J. (2001). Choice experiments: an overview of concepts and issues. In J. Bennett, \& R. Blamey (Eds.), The choice modelling approach to environmental valuation (pp. 13-36).

Louviere, J. J., \& Hensher, D. A. (1982). On the design and analysis of simulated choice or allocation experiments in travel choice modelling. Transportation Research Record, 890, 11-17.

Louviere, J. J., Hensher, D. A., \& Swait, J. D. (2000). Stated choice methods: Analysis and applications. Cambridge: Cambridge University Press.

Louviere, J. J., \& Woodworth, G. (1983). Design and analysis of simulated consumer choice and allocation experiments: a method based on aggregate data. Journal of Marketing Research, 20, 350-367.

Maddison, D., \& Foster, T. (2003). Valuing congestion costs in the British Museum. Oxford Economics Papers, 55(1), 173-190.

Mazzanti, M. (2002). Cultural heritage as multi-dimensional, multi-value and multiattribute economic good: toward a new framework for economic analysis and valuation. Journal of Socio-Economics, 31, 529-558.

Mazzanti, M. (2003). Valuing cultural heritage in a multi-attribute framework microeconomic perspectives and policy implications. Journal of SocioEconomics, 32, 549-569.

Mitchell, R. C., \& Carson, R. T. (1989). Using surveys to value public goods: The contingent valuation method. Washington, DC: Resources for the Future.

Morey, E. R., \& Rossmann, K. (2003). Using stated-preference questions to investigate variations in willingness to pay for preserving marble monuments: classic heterogeneity, random parameters, and mixture models. Journal of Cultural Economics, 27(3/4), 215-229.

Morey, E., Rossmann, K., Chestnut, L., \& Ragland, S. (1997). Valuing acid deposition injuries to cultural resources. Washington, DC: The National Acid Precipitation Assessment Program (NAPAP).

Morey, E., \& Rossmann, K. G. (1999). Combining random parameters and classic heterogeneity to estimate the benefits of decreasing acid deposition injuries to marble monuments in Washington, DC. (No. Working paper). Boulder: University of Colorado Department of Economics.
Morley, C. (1994). Experimental destination choice analysis. Annals of Tourism Research, 21(4), 780-791.

Morrison, M. (2000). Aggregation biases in stated preference studies. Australian Economic Papers, 39(2), 215-230.

Morrison, M., Bennett, J. W., \& Louviere, J. J. (1996). A comparison of stated preference techniques for estimating environmental values. (No. Choice modelling research report no. 1). Canberra: School of Economics and Management, University College, University of New South Wales.

Morrison, M., \& MacDonald, H. (2006, 7-10 February). Valuing biodiversity: a comparison of compensating surplus and compensating tax reallocation. In Paper presented at the 50th annual conference of the Australian Agricultural and Resource Economics, Sydney.

Navrud, S., \& Ready, R. C. (Eds.). (2002). Valuing cultural heritage: Applying environmental valuation techniques to historic buildings, monuments and artifacts. Cheltenham, UK: Edward Elgar.

Noonan, D. (2003). Contingent valuation and cultural resources: a meta-analytic review of the literature. Journal of Cultural Economics, 27, 159-176.

OPH. (2007). About. http://www.oph.gov.au/content.asp?pageID=7 Retrieved 02.04.07.

Rolfe, J. (1998). Complexities in the valuation of natural resources and the development of the choice modelling technique. Unpublished PhD dissertation, University of New South Wales, Canberra.

Rolfe, J. \& Bennett, J. (1996). Valuing international rainforests: A choice modelling approach. Canberra: School of Economics and Management, University College, University of New South Wales.

Rolfe, J., \& Bennett, J. (2001). Framing effects. In J. Bennett, \& R. Blamey (Eds.), The choice modelling approach to environmental valuation (pp. 202-224).

Rolfe, J., \& Windle, J. (2003). Valuing the protection of aboriginal cultural heritage sites. Economic Record, 79, S85-S95.

Rose, J. M., \& Bliemer, M. C. J. (2005). Constructing efficient choice experiments. (No. ITLS working paper ITLS-WP-05-07). Sydney: University of Sydney.

Sable, K. A., \& Kling, R. W. (2001). The double public good: a conceptual framework for "shared experience" values associated with heritage conservation. Journal of Cultural Economics, 25, 77-89.

Throsby, D. (2001). Economics and culture. Cambridge, UK: Cambridge University Press.

Tohmo, T. (2004). Economic value of a local museum: factors of willingness-to-pay Journal of Socio-Economics, 33, 229-240.

Train, K. (1999). Halton sequences for mixed logit. Berkeley: University of California. (No. Working paper).

Train, K. E. (2003). Discrete choice methods with simulation. Cambridge University Press.

Venkatachalam, L. (2004). The contingent valuation method: a review. Environmental Impact Assessment Review, 24(1), 89-124. 